\title{
Investigation of the situations affecting vocational school students' anxiety levels and academic achievements
}

\author{
Muhammet Bayraktar¹®, Mehmet Doğan²® \\ ${ }^{1}$ Department of Public Health, Niğde Ömer Halis University of School of Medicine, Niğde, Turkey \\ ${ }^{2}$ Department of Medical Services and Tecniques, Erciyes University, Halil Bayraktar Health Services Vocational School, Kayseri, Turkey
}

\begin{abstract}
Objectives: In this study, we aim to determine the prevalence of anxiety and evaluate its relationship with academic performance in a vocational school of health services students, which causes significant disability and loss of labor and is frequently seen with mood disorders in the society.

Methods: A sample was not selected for the research, it was aimed to reach all students. Of the 1093 students who are attending the school, $849(77.7 \%)$ students participated in the study. In order to determine the level of anxiety in students, a questionnaire form consisting of the Beck Anxiety Inventory and descriptive features were applied by the online survey method.

Results: Of the students; $80.1 \%$ are female, $98.1 \%$ are single, $57.1 \%$ are in their first year, and the average age is $20.25 \pm 1.81$. The total scale score was found $9.42 \pm 8.65$ and it was $9.90 \pm 8.69$ for female students and $7.49 \pm 8.24$ for male students. Variable levels of anxiety were detected in $38.8 \%$ of the participants. There was no statistically significant relation found between anxiety level and academic performance, but both anxiety levels and academic performances were affected by the gender of participants.

Conclusions: Making psychological evaluations of students while they are starting their higher education and checking their statuses periodically using standard self-report tools by using technological instruments; would make it possible to make necessary interventions by noticing the situations that may adversely affect their academic success, social life, mental and cognitive development in the early stages.

Keywords: vocational school, students, anxiety, grades
\end{abstract}

\section{A} nxiety's lifetime prevalence is reported to be between $13.6 \%$ and $28.8 \%$. It can cause significant disability and loss of labor and is frequently found in society along with mood disorders. It is a state of inquietude that can be observed as ranging from a mild level of uneasiness causing disquietude and tension to a state of apprehension that is severe enough to cause a sense of panic. It manifests itself with deteriorations in the physical, mental, somatic and cognitive areas of the person, with the expectation of a danger that may arise due to personal or environmental reasons [1-3].

If the anxiety of the person is within the ideal limits, support systems come into play and this mechanism provides an opportunity for the person to improve himself. It's a fact that if anxiety is not at the ideal level and increased, it can affect the mental and emotional state of the person and cause physical or psychological disorders, leading to negative experiences in the person's life [4]. This may lead to low performance in business life and it can also manifest itself 
as a decrease in lesson successes in school life as well. The relationship between increasing anxiety levels and academic performance needs to be examined extensively [5]. Because this relationship is important to provide appropriate medical and social supports in order to eliminate the low marks in students' grades, in case they exist.

In this study we planned to evaluate the prevalence of anxiety, relationship of anxiety levels and the academic performance in health services vocational school students.

\section{METHODS}

This descriptive and cross-sectional study was carried out at Erciyes University Halil Bayraktar Health Services Vocational School students during June 2020. All of the students studying in a total of ten programs in two different departments within the school were included in the study. The study was planned and carried out as voluntary participation in the online survey, as education and training activities were continued as distance education within the scope of Covid-19 epidemic preventive measures. Approval numbered 2020/322 from the ethics committee of Erciyes University along with permission from the directorate of the vocational school was obtained for the study. Information about the study was given to the participants on the online survey page and their informed consent was taken by their choosing the "I accept to participate in the study voluntarily" option on the same page. Students were asked to answer the participant information section consisting of six questions where socio-demographic information, school cumulative grade point average (CGPA), and the information about the department they were studying were collected; along with the Beck Anxiety Inventory (BAI), which consists of 21 questions that used to measure anxiety states. The BAI is defined as a reliable self-report tool for measuring participants' anxiety levels. The scale consists of querying 21 symptoms. Participants are asked to state to what extent they feel uncomfortable with regards to each item "during the past week, including today". The answers are scored on a scale of 0 to 3 ranging from "not at all" to "severely", resulting in a total score of from 0 to 63 . While the total scale score between 0 to 9 points is interpreted as normal anxiety level, from 10 to 18 points are evaluated as mild-moderate, from 19 to 29 points are moderate-severe and from 30 to 63 points are considered as serious anxiety levels. The developers of the scale reported a high level of internal consistency (Cronbach alpha $=$ $0.92)$ and a good test-retest correlation $(r=0.75)$ [6$8]$. The results of the validity and reliability study of the Turkish version of BAI also support its use as a reliable and valid measure of anxiety in the Turkish population [9]. In our study, Cronbach's alpha value was found to be 0.90 .

\section{Statistical Analysis}

Statistical analyses of the collected data were done with the SPSS program. Descriptive statistics were presented as mean \pm standard deviation, median (min, max), frequency distribution and percentages. The relationship between anxiety level and other independent variables were evaluated with Chi-square tests. Since the data did not match the normal distribution, Mann-Whitney and Kruskal-Wallis tests were used to compare the mean values of the anxiety score among different subgroups and to examine from which independent variables they were affected. The relationship between cumulative grade point averages and other independent variables were evaluated with Chi-square tests. For all statistical tests, values where $p<0.05$ were considered as being significant.

For post-hoc analysis, Chi-Square values were calculated by using residual $(Z)$ values, $p$ values were calculated from these Chi-Square values and Bonferroni correction was applied to these $p$ values [10-11].

\section{RESULTS}

From 1093 students attending 10 different programs within the school, $849(77.7 \%)$ students participated in the study. According to Table 1, of the participants; $80.1 \%$ were women, $98.1 \%$ were single, $57.1 \%$ were in the first year of their education. The average age of the participants was $20.25 \pm 1.81$ (min: 18, max: 30). While the total scale score was calculated as $9.42 \pm 8.65$ (min: 0, max: 60), varying levels of anxiety from mild-moderate to serious were detected in $38.8 \%$ of the participants. As it could also be seen from Table 1; the changes in the average scale score in relation to the gender of the participants, the 
Table 1. Changes in the BAI total score according to the characteristics of the participants

\begin{tabular}{|c|c|c|c|c|c|c|c|}
\hline \multirow[t]{2}{*}{$\mathrm{n}=\mathbf{8 4 9}$} & \multicolumn{5}{|c|}{ BAI total score } & \multirow{2}{*}{$\begin{array}{c}\text { Kruskal-Wallis H / } \\
\text { Mann-Whitney U }\end{array}$} & \multirow[t]{2}{*}{$p$ value } \\
\hline & $\mathbf{n}$ & $\%$ & $\overline{\mathbf{x}}$ & SD & Mean rank & & \\
\hline Genders & & & & & & $45327.000^{\mathrm{a}}$ & $<0.001$ \\
\hline Female & 680 & 80.1 & 9.90 & 8.69 & 442.84 & & \\
\hline Male & 169 & 19.9 & 7.49 & 8.24 & 353.21 & & \\
\hline \multicolumn{6}{|c|}{ Years of education } & $87528.000^{\mathrm{a}}$ & 0.834 \\
\hline First & 485 & 57.1 & 9.30 & 8.35 & 426.53 & & \\
\hline Second & 364 & 42.9 & 9.59 & 9.05 & 422.96 & & \\
\hline \multicolumn{6}{|c|}{ Cumulative grade point averages (CGPA) } & $4.008^{\mathrm{b}}$ & 0.405 \\
\hline$<=2.00$ & 37 & 4.4 & 9.57 & 9.44 & 414.03 & & \\
\hline $2.01-2.50$ & 119 & 14.0 & 10.42 & 10.68 & 432.49 & & \\
\hline $2.51-3.00$ & 271 & 31.9 & 9.37 & 8.52 & 423.07 & & \\
\hline $3.01-3.50$ & 342 & 40.3 & 8.77 & 7.82 & 413.85 & & \\
\hline $3.51-4.00$ & 80 & 9.4 & 10.81 & 8.68 & 473.18 & & \\
\hline Ages & & & & & & $10.132^{\mathrm{b}}$ & 0.072 \\
\hline 18 & 65 & 7.7 & 10.85 & 7.61 & 491.82 & & \\
\hline 19 & 220 & 25.9 & 9.36 & 8.71 & 425.14 & & \\
\hline 20 & 296 & 34.9 & 9.76 & 8.79 & 435.98 & & \\
\hline 21 & 160 & 18.8 & 8.54 & 7.98 & 399.76 & & \\
\hline 22 & 52 & 6.1 & 9.65 & 9.61 & 416.37 & & \\
\hline $23+$ & 56 & 6.6 & 8.50 & 9.68 & 368.96 & & \\
\hline
\end{tabular}

${ }^{\mathrm{a}}$ Mann Whitney U, ${ }^{\mathrm{b}}$ Kruskal Wallis H, BAI = Beck Anxiety Inventory

programs they studied, the number of years of their education, their CGPAs, and their ages were observed and they were tested for statistical significance. Accordingly, statistically significant relations were found in the change of total scale score with participants' genders and anxiety levels $(p<0.001)$.

When we looked at which of the participants' gender, school year, CPGA, age characteristics were related with the level of anxiety calculated; it is seen in Table 2 that there is no statistically significant relationship between the calculated anxiety levels and these independent variables $(p>0.05)$.

When we look at which independent variables CPGA is affected in Table 3, it is seen that only the differences regarding the gender of the participants are statistically significant. CPGA was calculated as 3.48 \pm 0.94 in females and $2.89 \pm 1.02$ in male participants. Performed post-hoc analyses revealed that the afore- mentioned statistical significance between gender and CPGA was due to the 2.01-2.50 and 3.01-3.50 CPGA levels. While the CGPA is statistically significantly affected by the school programs that students were getting their education $(\mathrm{x} 2(36)=101.309, p<0.001)$; it was determined that there was no relationship between the level of anxiety and the school programs that students were getting their education ( $p>0.05$, Fisher's exact test).

\section{DISCUSSION}

The prevalence of anxiety, which was determined as $38.8 \%$ among the students participating in the study, was similarly found to be $40 \%$ in another recent study using the same scale. This rate is lesser than the previous studies conducted in different countries at dif- 
Table 2. Changes in the anxiety level according to the characteristics of the participants

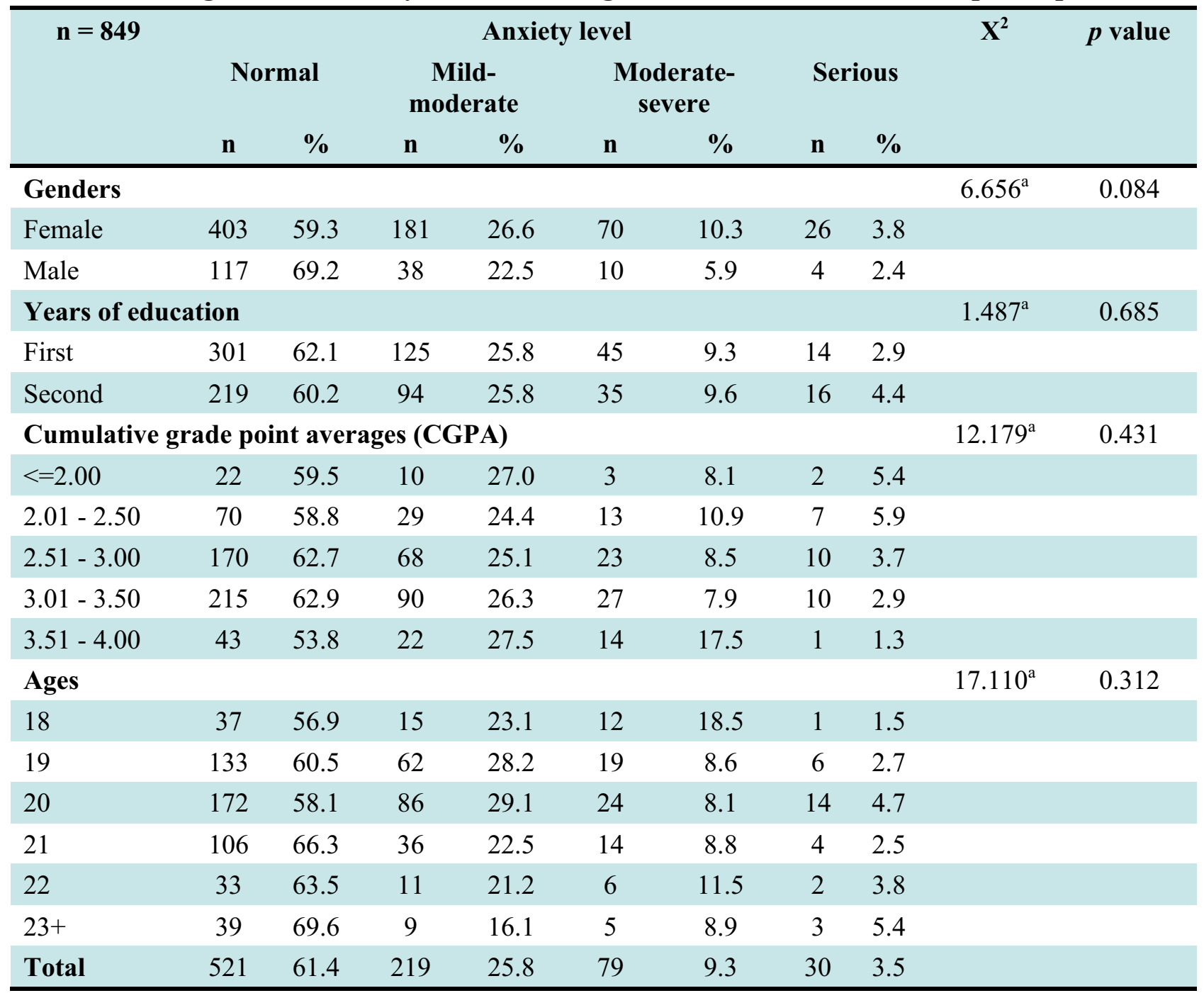

aPearson's chi-squared test $\left(X^{2}\right),{ }^{\text {b}}$ Fisher's Exact

ferent times [5,12-18]. When the studies on the subject are examined, as the anxiety level of women is higher than that of men; in studies with a high rate of women participants, it is seen that the level of anxiety increases in the study population. But in our study, although four-fifths of the participants were women, the total anxiety level was found to be lower than in other studies $[16,19,20]$. This can be accepted as evidence that the only variable that affects the level of anxiety is not gender. There are other studies supporting this idea, reported that there is no statistically significant difference at the anxiety level that can be associated with gender $[12,21,22]$.

As $98.1 \%$ of the participants in the study were single, there was not any statistical tests applied for making comparisons of changes with marital status to avoid statistically erroneous results. However in a study conducted with students, it was stated that the prevalence of anxiety was higher in singles. But in another research conducted with patients; while it was stated that anxiety disorders were found to be more common in divorced, widowed, or separated people in previous field studies, according to their own findings the diagnosis of anxiety disorder was reported to be significantly higher in married people than in singles $[2,18]$. This suggests that the marital status of the participants does not alone affect the anxiety state and other factors may also have a role. There was no statistically significant difference between the year of study with the total anxiety scores and categorical anxiety levels. In the literature, some studies state a statistical relationship between the class studied and 
Table 3. Changes in the cumulative grade point averages according to the characteristics of the participants

\begin{tabular}{|c|c|c|c|c|c|c|c|c|c|c|c|c|}
\hline \multirow[t]{3}{*}{$\mathrm{n}=849$} & \multicolumn{10}{|c|}{ Cumulative grade point average } & \multirow[t]{3}{*}{$X^{2}$} & \multirow[t]{3}{*}{$p$ value } \\
\hline & \multicolumn{2}{|c|}{$<=2.00$} & \multicolumn{2}{|c|}{$2.01-2.50$} & \multicolumn{2}{|c|}{$2.51-3.00$} & \multicolumn{2}{|c|}{$3.01-3.50$} & \multicolumn{2}{|c|}{$3.51-4.00$} & & \\
\hline & $\mathbf{n}$ & $\%$ & $\mathbf{n}$ & $\%$ & $\mathbf{n}$ & $\%$ & $\mathbf{n}$ & $\%$ & $\mathbf{n}$ & $\%$ & & \\
\hline Genders & & & & & & & & & & & $52.166^{\mathrm{a}}$ & $<0.001$ \\
\hline Female & 21 & 3.1 & 76 & 11.2 & 210 & 30.9 & 300 & 44.1 & 73 & 10.7 & & \\
\hline Male & 16 & 9.5 & 43 & 25.4 & 61 & 36.1 & 42 & 24.9 & 7 & 4.1 & & \\
\hline Years of education & & & & & & & & & & & $2.159^{\mathrm{a}}$ & 0.706 \\
\hline First & 22 & 4.5 & 67 & 13.8 & 159 & 32.8 & 187 & 38.6 & 50 & 10.3 & & \\
\hline Second & 15 & 4.1 & 52 & 14.3 & 112 & 30.8 & 155 & 42.6 & 30 & 8.2 & & \\
\hline Anxiety levels & & & & & & & & & & & $11.591^{\mathrm{c}}$ & 0.455 \\
\hline Normal & 22 & 4.2 & 70 & 13.5 & 170 & 32.7 & 215 & 41.3 & 43 & 8.3 & & \\
\hline Mild- moderate & 10 & 4.6 & 29 & 13.2 & 68 & 31.1 & 90 & 41.1 & 22 & 10.0 & & \\
\hline Moderate- severe & 3 & 3.8 & 13 & 16.3 & 23 & 29.1 & 28.8 & 33.8 & 14 & 17.5 & & \\
\hline Serious & 2 & 6.7 & 7 & 23.3 & 10 & 33.3 & 10 & 33.3 & 1 & 3.3 & & \\
\hline Ages & & & & & & & & & & & $26.284^{\mathrm{a}}$ & 0.157 \\
\hline 18 & 1 & 1.5 & 9 & 13.8 & 23 & 35.4 & 26 & 40.0 & 6 & 9.2 & & \\
\hline 19 & 8 & 3.6 & 35 & 15.9 & 69 & 31.4 & 86 & 39.1 & 22 & 10.0 & & \\
\hline 20 & 14 & 4.7 & 34 & 11.5 & 88 & 29.7 & 131 & 44.3 & 29 & 9.8 & & \\
\hline 21 & 7 & 4.4 & 18 & 11.3 & 58 & 36.3 & 68 & 42.5 & 9 & 5.6 & & \\
\hline 22 & 2 & 3.8 & 9 & 17.3 & 20 & 38.5 & 16 & 30.8 & 5 & 9.6 & & \\
\hline $23+$ & 5 & 8.9 & 14 & 25.0 & 13 & 23.2 & 15 & 26.8 & 9 & 16.1 & & \\
\hline Total & 37 & 4.4 & 119 & 14.0 & 271 & 31.9 & 342 & 40.3 & 80 & 9.4 & & \\
\hline
\end{tabular}

aPearson's chi-squared test $\left(X^{2}\right),{ }^{\text {b}}$ Fisher's Exact, ${ }^{\mathrm{c}}$ Monte Carlo

anxiety status, whereas in some studies there is no significant difference reported. In the studies that state that there is a relation between the class and anxiety level, while some researchers reported that the level of anxiety was higher in the first grades, the other researchers reported that in the final grades [16, 21,23].

No significant relationship was found between the CPGAs of the participants with the total BAI and the anxiety levels. On the other hand, while we were observing the changes in independent variables and their effects on the students' academic achievements by looking at CPGAs; a statistically significant relationship was determined between the CPGAs with the gender of the participants, and the program in which they were educated. Accordingly, it could be said that being a woman has positive effects on academic suc- cess in students (Table 3). On the other hand, the relationship between the program studied and CPGA might be related to the ease or difficulty of the courses within the scope of the program, the simplicity or complexity of the applications carried out within the scope of education as well as other factors. In order for this to be understood, other investigations should be made examining the possible causalities.

While there was no significant difference in the change of total anxiety scores and categorical anxiety levels related to ages of participants in this study; it was reported that high anxiety scores were associated with increasing age and the prevalence of anxiety increased significantly at older ages in another study [18]. Again, there is information in the literature that anxiety disorders start especially in the $20 \mathrm{~s}$, and the 
incidence increases with age [2].

\section{Limitations}

Studies examining the effects of various variables such as emotion and anxiety state and belief state, physical activity level, body mass index, familial features, etc. are present in the literature. The limitations observed in all cross-sectional studies are valid both for these other studies and as well for this study. Although it was carried out with a large number of participants from ten different programs, the information in the study was collected from students of the vocational school of health services. Different results can be obtained in studies conducted in other schools. Also, participation in the study was on a voluntary basis. And in the studies carried out in the form of the participation of volunteers; it is a known phenomenon that those who have the examined feature are not willing to participate in the study as much as those who do not [24]. In addition, the relationship of variables examined within the scope of the study with anxiety states of the individuals was only examined using a self-report questionnaire, without processes that make it possible to make a definitive diagnosis, such as clinical interviews. Despite all these limitations, it is important to carry out studies that make it possible to follow the emotional and anxiety states of the students throughout their education life. Because stress, emotion, and anxiety cases that were not diagnosed in the early stages during the studentship period; may negatively affect the quality of life and job performance of individuals when they get into professional life thereafter [25].

\section{CONCLUSION}

It is appropriate to make psychological evaluations of students while they are starting their higher education and then to check their statuses regularly during the education; within the periods determined by specialists, with standard self-report tools that are tested for reliability, and also by using technological instruments for evaluations whenever it is possible. In this way, it will be possible to make necessary interventions by noticing the situations that may adversely affect their academic success, social life, mental and cognitive development in the early stages.

\section{Authors' Contribution}

Study Conception: MB; Study Design: MB; Supervision: $\mathrm{MB}, \mathrm{MD}$; Funding: $\mathrm{MB}, \mathrm{MD}$; Materials: MB; Data Collection and/or Processing: MB, MD; Statistical Analysis and/or Data Interpretation: MB; Literature Review: MB; Manuscript Preparation: MB, MD and Critical Review: MB, MD.

\section{Conflict of interest}

The authors disclosed no conflict of interest during the preparation or publication of this manuscript. Authors declare that they have no conflict of interest.

\section{Financing}

The authors disclosed that they did not receive any grant during conduction or writing of this study.

\section{REFERENCES}

1. Öztürk MO, Uluşahin A. Ruh Sağlığı ve Bozuklukları. 13. Bask1, Ankara: Nobel Tıp Kitapevleri; 2015.

2. Özcan M, Uğuz F, Çilli AS. [The prevalence of generalized anxiety disorder and comorbidity among psychiatric outpatients]. Türk Psikiyatri Dergisi 2006;17:276-85. [Article in Turkish]

3. Diagnostic and statistical manual of mental disorders: DSM5. Washington, DC: American Psychiatric Publishing; 2013.

4. Türker E. Koroner Anjiyografi Yapılan Hastaların ve Eşlerinin Anksiyeteleri, Ankara Üniversitesi, Sağlık Bilimleri Enstitüsü, Hemşirelik Ana Bilim Dalı, Yüksek Lisans Tezi, Ankara, 2015.

5. Junaid M, Auf A, Shaikh K, Khan N, Abdelrahim S. Correlation between academic performance and anxiety in medical students of Majmaah University - KSA. J Pak Med Assoc 2020;70:865-8.

6. Beck AT, Epstein N, Brown G, Steer RA. An inventory for measuring clinical anxiety: Psychometric properties. J Consult Clin Psychol 1988;56:893-7.

7. Beck AT, Steer RA. Beck Anxiety Inventory Manual. San Antonio: The Psychological Corporation Harcourt Brace Jovanovich, Inc.; 1990.

8. Creamer M, Foran J, Bell R. The Beck Anxiety Inventory in a non-clinical sample. Behav Res Ther 1995;33:477-85.

9. Ulusoy M, Sahin NH, Erkmen H. The Beck anxiety inventory: psychometric properties. J Cogn Psychother 1998;12:163-72.

10. Beasley TM, Schumacker RE. Multiple regression approach to analyzing contingency tables: Post hoc and planned comparison procedures. J Exp Educ 1995;64:79-93.

11. Garcia-Perez MA, Nunez-Anton V. Cellwise residual analysis in two-way contingency tables. Educ Psychol Meas 2003;63:82539.

12. Inam SNB, Saqib A, Alam E. Prevalence of anxiety and depression among medical students of private university. J Pak Med Assoc 2003;53:44-6.

13. Mehanna Z, Richa S. [Prevalence of anxiety and depressive 
disorders in medical students. Transversal study in medical students in the Saint-Joseph University of Beirut]. Encephale 2006;32(6Pt1):976-82. [Article in French]

14. Yusoff MSB, Rahim AFA, Baba AA, Ismail SB, Pa MNM, Esa AR. Prevalence and associated factors of stress, anxiety and depression among prospective medical students. Asian J Psychiatr 2013;6:128-33.

15. Singh I, Jha A. Anxiety, optimism and academic achievement among students of private medical and engineering colleges: a comparative study. J Educ Dev Psychol 2013;3:222-33.

16. Saravanan C, Wilks R. Medical students' experience of and reaction to stress: the role of depression and anxiety. ScientificWorldJournal 2014;2014:737382.

17. Manchevska S, Pluncevic-Gligoroska J. The prevalence of high anxiety and substance Use in university students in the republic of Macedonia. Prilozi 2014;35:67-74.

18. Wahed WY, Hassan SK. Prevalence and associated factors of stress, anxiety and depression among medical Fayoum University students. Alexandria J Med 2017;53:77-84.

19. Kars V, Arslan N, Erik L, Avcı N, Bucaktepe PG, Celepkolu T, Şahin HA. [The problems during choice of profession and comparison of these problems with anxiety and depression in final year of high school students]. Dicle Med J 2014;41:187-90. [Article in Turkish]

20. Ayaz E, Varol G. [Examination of factors related to dental anxiety level in 1st grade students in health high school of Namik Kemal University vocational school of health services]. Namik Kemal Tip Dergisi 2018;6:96-103. [Article in Turkish]

21. Gümüş F, Zengin L. [Anxiety, depressive symptom frequency and related factors in nursing students]. Van Med J 2018;25:52734. [Article in Turkish]

22. Ölçücü B, Vatansever Ş, Özcan G, Çelik A, Paktaş Y. [The relationship between depression, anxiety and physical activity level among university students]. Uluslararası Türk Eğitim Bilimleri Dergisi 2015;April 2015:294-303. [Article in Turkish]

23. Bilgel N, Bayram N. Turkish version of the depression anxiety stress scale (DASS-42): psychometric properties. Arch Neuropsychiatry 2010;47:118-26.

24. Vernon SW, Roberts RE, Sul Lee EUN. Ethnic status and participation in longitudinal health surveys. Am J Epidemiol 1984;119:99-113.

25. Rosenthal JM, Okie S. White Coat, Mood indigo - depression in medical school. N Eng J Med 2005;353:1085-8. 